\title{
Chemical Transformation of Crystalline Hafnium Tetrafluoride Studied by Perturbed Angular Correlation Spectroscopy
}

\author{
Chandi Charan C. Dey \\ Saha Institute of Nuclear Physics 1/AF, Bidhannagar, Kolkata - 700 064, India \\ Reprint requests to C.C.D.; Fax: 9133 23374637; E-mail: chandicharan.dey@ saha.ac.in \\ Z. Naturforsch. 64a, 739 - 744 (2009); received December 12, 2008 / revised April 16, 2009
}

\begin{abstract}
The chemical transformation of the trihydrate hafnium tetrafluoride crystal has been studied with varying temperature using the time-differential perturbed angular correlation technique. The $133-$ $482 \mathrm{keV} \gamma-\gamma$ cascade of ${ }^{181} \mathrm{Ta}$ after the $\beta^{-}$-decay of ${ }^{181} \mathrm{Hf}$ has been selected and a four detector $\mathrm{BaF}_{2}-\mathrm{BaF}_{2}$ coincidence set up has been used for measurements. The crystal was produced by evaporating a solution of $\mathrm{HfF}_{6}{ }^{2-}$ complex in $\mathrm{HF}$ at room temperature. Contrary to the earlier report, it has been found that the trihydrate hafnium tetrafluoride compound dehydrates directly to $\mathrm{HfF}_{4}$ without producing any intermediate monohydrate and present results do not support the earlier idea that two water molecules of $\mathrm{HfF}_{4} \cdot 3 \mathrm{H}_{2} \mathrm{O}$ are loosely bound. Present investigations exhibit a superheated state for the hafnium tetrafluoride crystal. In dehydrated $\mathrm{HfF}_{4}$, two different $\mathrm{Hf}$ sites have been observed which suggests two different structures for the anhydrous $\mathrm{HfF}_{4}$.
\end{abstract}

Key words: Hydrated Hafnium Tetrafluoride; Dehydration Temperature; Time-Differential Perturbed Angular Correlation; Nuclear Quadrupole Interactions.

\section{Introduction}

The dehydration process of crystallized trihydrate hafnium tetrafluoride is not fully understood. In fact, from earlier studies, the chemical transformation of $\mathrm{HfF}_{4} \cdot 3 \mathrm{H}_{2} \mathrm{O}$ gave contradictory results. From chemical analysis study, Rickard and Water [1] showed that this compound was transformed to monohydrate hafnium fluoride $\left(\mathrm{HfF}_{4} \cdot \mathrm{H}_{2} \mathrm{O}\right)$ on heating at $373 \mathrm{~K}$ in vacuum and monohydrate oxifluoride $\left(\mathrm{Hf}_{2} \mathrm{OF}_{6} \cdot \mathrm{H}_{2} \mathrm{O}\right)$ at $373 \mathrm{~K}$ in air. Gaudreau [2] observed that $\mathrm{HfF}_{4} \cdot 3 \mathrm{H}_{2} \mathrm{O}$ dehydrates to $\mathrm{HfF}_{4} \cdot \mathrm{H}_{2} \mathrm{O}$ at $353 \mathrm{~K}$ in air. On the other hand, Martínez et al. [3,4], from time-differential perturbed angular correlation (TDPAC) measurements showed that final dehydrated product of $\mathrm{HfF}_{4} \cdot 3 \mathrm{H}_{2} \mathrm{O}$ was $\mathrm{HfF}_{4}$ and it was produced at the still lower temperature of $330 \mathrm{~K}$. These authors $[3,4]$ found that in the transformation from $\mathrm{HfF}_{4} \cdot 3 \mathrm{H}_{2} \mathrm{O}$ to $\mathrm{HfF}_{4}$, monohydrate $\mathrm{HfF}_{4} \cdot \mathrm{H}_{2} \mathrm{O}$ was formed as an intermediate product. They studied the reverse process of hydration also and found that $\mathrm{HfF}_{4}$ transforms back to $\mathrm{HfF}_{4} \cdot 3 \mathrm{H}_{2} \mathrm{O}$ through the intermediate monohydrate and from this reverse reaction Martínez et al. [3] determined the rate constant for the hydration process. Beside this, earlier studies show discrepancies regarding the dehydration temperature of $\mathrm{HfF}_{4} \cdot 3 \mathrm{H}_{2} \mathrm{O}$. For this compound, the same group $[3,4]$ reported two different dehydra- tion temperature of $330 \mathrm{~K}$ [3] and $393 \mathrm{~K}$ [4]. With an aim to resolve the above discrepancies, the trihydrate hafnium tetrafluoride has been studied by TDPAC with varying temperature in the range of $298 \mathrm{~K}$ to $363 \mathrm{~K}$ after crystallizing it at room temperature. Interestingly, in the present study it has been found that dehydration of $\mathrm{HfF}_{4} \cdot 3 \mathrm{H}_{2} \mathrm{O}$ starts at $343 \mathrm{~K}$ and it transforms to anhydrous $\mathrm{HfF}_{4}$ completely at $363 \mathrm{~K}$, but it is not routed through the intermediate $\mathrm{HfF}_{4} \cdot \mathrm{H}_{2} \mathrm{O}$. The dehydration from $\mathrm{HfF}_{4} \cdot 3 \mathrm{H}_{2} \mathrm{O}$ to $\mathrm{HfF}_{4}$ takes place directly. The monohydrate $\mathrm{HfF}_{4} \cdot \mathrm{H}_{2} \mathrm{O}$ was not observed in the crystallized trihydrate at any temperature from 298 to $363 \mathrm{~K}$ as well as in the dehydrated $\mathrm{HfF}_{4}$ compound. So, the chemical transformation from $\mathrm{HfF}_{4} \cdot 3 \mathrm{H}_{2} \mathrm{O}$ to $\mathrm{HfF}_{4} \cdot \mathrm{H}_{2} \mathrm{O}$ observed by Gaudreau [2] or its transformation to anhydrous $\mathrm{HfF}_{4}$ through the intermediate $\mathrm{HfF}_{4} \cdot \mathrm{H}_{2} \mathrm{O}$ as observed by Martínez et al. [3] is not supported from present measurements. It has been found also that this trihydrate compound can remain stable in the super heated state at 343 and $353 \mathrm{~K}$ although its dehydration temperature has been found to be $343 \mathrm{~K}$.

\section{Principle of the TDPAC Technique}

The time-differential pertubed angular correlation (TDPAC) technique is based on substituting a small or trace amount of radioactive isotope into a well- 
defined chemical environment in a crystal [5]. The nuclear electromagnetic moments (electric quadrupole or magnetic dipole) of the probe isotope interact with the electric field gradient or the magnetic field produced at the nuclear site by the surrounding environment. Due to the interaction of the surrounding electric field gradient generated at the nuclear site with the nuclear quadrupole moment, the $\gamma-\gamma$ angular correlation is perturbed.

The perturbation function $G_{k}(t)$ for $k=2$ can be written as [6]

$$
\begin{aligned}
G_{2}(t)=\left\{S_{20}+\sum_{i}^{3} S_{2 i} \cos \left(\omega_{i} t\right)\right. & \\
\cdot & \left.\exp \left(-\delta \omega_{i} t\right) \exp \left[\frac{\left(\omega_{i} \tau_{\mathrm{R}}\right)^{2}}{2}\right]\right\} .
\end{aligned}
$$

In case of ${ }^{181} \mathrm{Hf}$, a consideration of $k=2$ only is quite reasonable because of the much smaller value of $A_{4}$ compared to $\mathrm{A}_{2}\left(\mathrm{~A}_{2}=-0.288, A_{4}=-0.076\right.$ [6]) for the $133-482 \mathrm{keV}$ cascade. A value of $G_{2}(t)=1$ corresponds to no perturbation. The above expression for $G_{2}(t)$ is valid for a polycrystalline sample with $I=5 / 2$ for the intermediate state. The frequencies $\omega_{i}$ correspond to transitions between the sublevels of the intermediate state which arise due to quadrupole interaction. Details about the TDPAC technique have been reviewed by Schatz and Weidinger [6]. In the analysis of experimental data, the source inhomogeneities arising from lattice imperfections or chemical effects have been taken into account through the first exponent in (1). Finite time resolution $\left(\tau_{\mathrm{R}}\right)$ of the coincidence system has also been considered through the second exponent in (1).

If more than one interaction frequencies are present in the sample due to the existence of either various inequivalent sites within the same compound or a mixture of different compounds, the perturbation function can be written as

$$
G_{2}(t)=\sum_{i} f_{i} G_{2}^{i}(t),
$$

where $f_{i}$ is the fraction of the $i$-th component. A fitting to expression (1) determine the maximum component $V_{z z}$ of the electric field gradient through the relation

$$
\omega_{\mathrm{Q}}=\frac{e Q V_{z z}}{4 I(2 I-1) \hbar},
$$

$\omega_{\mathrm{Q}}$ is the quadrupole frequency and $Q$ is the nuclear quadrupole moment. For an axially symmetric electric field gradient $(\eta=0)$ this is related to $\omega_{1}, \omega_{2}$, and $\omega_{3}$ as $\omega_{\mathrm{Q}}=\omega_{1} / 6=\omega_{2} / 12=\omega_{3} / 18$. For $\eta \neq 0$, this simple relation of $\omega_{1}: \omega_{2}: \omega_{3}=1: 2: 3$ does not hold and a more complex relation between $\omega_{\mathrm{Q}}$ and $\omega_{1}$ arises [3]. However, in this case also the sum rule $\omega_{3}=\omega_{1}+\omega_{2}$ holds. The asymmetry parameter is defined as the ratio $\eta=\left(V_{x x}-V_{y y}\right) / V_{z z}$ and its value lies between 0 and 1 .

\section{Experimental}

The trihydrate hafnium tetrafluoride was prepared from hafnium metal by dissolving in concentrated hydrofluoric acid and drying at room temperature. For this, a small piece of hafnium metal (Zr impurity nominally $3 \%$ ) procured from M/S Alfa Aesar was activated in the reactor at Mumbai, India, through the capture of thermal neutron to produce the radioisotope ${ }^{181} \mathrm{Hf}$. The active hafnium metal was then dissolved in concentrated hydrofluoric acid (HF) and allowed to dry at room temperature for $2-3$ days. It is known that in $\mathrm{HF}$, hafnium metal forms an octahedral complex of $\mathrm{HfF}_{6}{ }^{2-}$ in the solution. After the solution is dried completely it is used for TDPAC measurements. It has been observed that when hafnium metal is dissolved in concentrated $\mathrm{HF}$ and dried at an elevated temperature $\left(\geq 35^{\circ} \mathrm{C}\right)$ the compound $\mathrm{HfF}_{4} \cdot 3 \mathrm{H}_{2} \mathrm{O}$ is not produced, but an $\mathrm{HF}$ adducted compound $\mathrm{HfF}_{4} \cdot \mathrm{HF} \cdot 2 \mathrm{H}_{2} \mathrm{O}$ is formed.

For TDPAC measurements, a four detector TDPAC spectrometer with $\mathrm{BaF}_{2}$ detectors of crystal sizes $50.8 \times 50.8 \mathrm{~mm}^{2}$ has been used. The time resolution of the experimental set up was $\sim 1 \mathrm{~ns}$ for the selected $\gamma$-rays of ${ }^{181} \mathrm{Ta}$. Details about the experimental set up and data analysis have been described earlier [7]. For temperature variation of the sample, it was put in contact with a close cycle circulating liquid. The temperature of the liquid was varied precisely with a controlled cooling unit of M/S Julabo, Germany, with a temperature accuracy of better than $1{ }^{\circ} \mathrm{C}$.

The experimental set up has been tested with the liquid sample of Hf metal in HF. This gives a flat perturbation as reported earlier [8]. Due to cubic symmetry of the octahedral complex $\mathrm{HfF}_{6}{ }^{2-}$ it produces no electric field gradient at the nuclear site resulting an unperturbed angular correlation in HF.

\section{Results and Discussion}

The TDPAC spectrum in the crystallized sample taken at room temperature is shown in Figure 1. An analysis of the spectrum shows that it has actually 

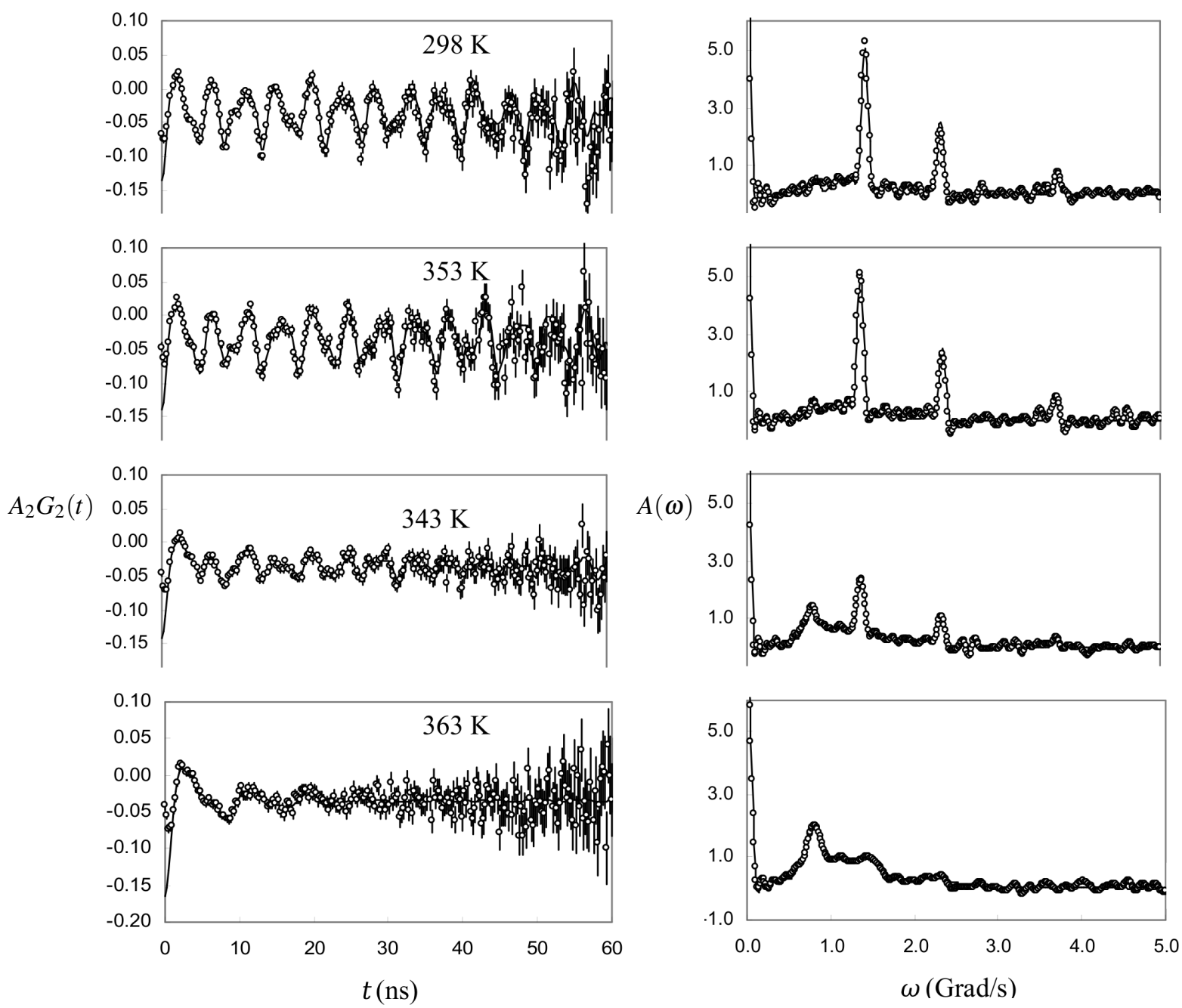

Fig. 1. TDPAC spectra (left) and the corresponding Fourier spectra (right) at different temperatures. The spectrum at $343 \mathrm{~K}$ taken after the measurement at $353 \mathrm{~K}$ shows a marked difference and indicates a dehydration of the sample. At $353 \mathrm{~K}$, however, it remained stable indicating a superheated state. At $363 \mathrm{~K}$, the spectrum indicates a complete dehydration.

four frequency components although the major component $(54 \%)$ was found to be due to $\mathrm{HfF}_{4} \cdot 3 \mathrm{H}_{2} \mathrm{O}$. The quadrupole frequency and anisotropy parameter for this component are in good agreement with the earlier reported values (Table 1). Among other components, the third strongest component (13\%) can be identified as $\mathrm{Hf}_{2} \mathrm{OF}_{6} \cdot 2 \mathrm{H}_{2} \mathrm{O}$ by comparing the quadrupole frequency and the anisotropy parameter obtained with the values reported earlier by Thies et al. [9] and from their assignment of this component. In addition to these two components, two others (Table 1) have been observed. These have been identified from measurements at different temperatures up to $363 \mathrm{~K}$ when the sample be- comes anhydrous. However, in the crystallized sample no component corresponding to monohydrate tetrafluoride has been observed with the characteristic values of $\omega_{\mathrm{Q}}=211 \mathrm{Mrad} / \mathrm{s}$ and $\eta=0.50$ [3]. More accurate values of $\omega_{\mathrm{Q}}=217.8$ (4) $\mathrm{Mrad} / \mathrm{s}$ and $\eta=0.487$ (4) for the compound $\mathrm{HfF}_{4} \cdot \mathrm{H}_{2} \mathrm{O}$ have been found from our recent measurement. The earlier results [3], however, overlap with the new results within their errors. Since the present sample does not contain the monohydrate component, it is very suitable to study the dehydration process and to observe the dehydrated product that is produced on heating at different temperature, particularly, to determine whether $\mathrm{HfF}_{4} \cdot 3 \mathrm{H}_{2} \mathrm{O}$ 
Table 1. Results of TDPAC measurements in hafnium tetrafluoride at different temperatures.

\begin{tabular}{|c|c|c|c|c|c|c|}
\hline $\begin{array}{l}\text { Temp. } \\
(\mathrm{K})\end{array}$ & compound & $\begin{array}{c}\omega_{\mathrm{Q}} \\
(\mathrm{Mrad} / \mathrm{s})\end{array}$ & $\eta$ & $\begin{array}{c}\delta \\
(\%) \\
\end{array}$ & $\begin{array}{l}\text { site } \\
(\%)\end{array}$ & Ref. $^{\dagger}$ \\
\hline \multirow[t]{6}{*}{298} & $\mathrm{HfF}_{4} \cdot 3 \mathrm{H}_{2} \mathrm{O}$ & $201.8(2)$ & $0.427(4)$ & 0 & $54(1)$ & \\
\hline & & $203(1)$ & $0.43(1)$ & $<2$ & & [3] \\
\hline & $\mathrm{HfF}_{4}$ (Site II) & $124(3)$ & $0.75(3)$ & $9(1)$ & $25(1)$ & \\
\hline & $\mathrm{Hf}_{2} \mathrm{OF}_{6} \cdot \mathrm{H}_{2} \mathrm{O}$ & $158(1)$ & $0.76(3)$ & $1.9(8)$ & $13(1)$ & \\
\hline & & $159(2)$ & $0.71(2)$ & $9(2)$ & & [9] \\
\hline & $\mathrm{HfF}_{4}$ (Site I) & $121(2)$ & $0.36(3)$ & 0 & $8(1)$ & \\
\hline \multirow[t]{4}{*}{323} & & $201.9(2)$ & $0.395(5)$ & 0 & $55(1)$ & \\
\hline & & $116(2)$ & $0.68(3)$ & $8(2)$ & $24(1)$ & \\
\hline & & $159(1)$ & $0.74(3)$ & $1.7(8)$ & $14(1)$ & \\
\hline & & $119(2)$ & $0.29(5)$ & 0 & $7(1)$ & \\
\hline \multirow[t]{4}{*}{333} & & $201.8(2)$ & $0.392(3)$ & 0 & $56(1)$ & \\
\hline & & $119(4)$ & $0.76(5)$ & $10(2)$ & $22(1)$ & \\
\hline & & $156(2)$ & $0.74(4)$ & $2(1)$ & $12(1)$ & \\
\hline & & $117(1)$ & $0.38(2)$ & 0 & $9(1)$ & \\
\hline \multirow[t]{4}{*}{343} & & 201.8(2) & $0.377(6)$ & 0 & $53(2)$ & \\
\hline & & $116(3)$ & $0.74(3)$ & $9(2)$ & $27(1)$ & \\
\hline & & 154(1) & $0.77(3)$ & $1.1(8)$ & $14(2)$ & \\
\hline & & $116(2)$ & $0.33(5)$ & 0 & $5(2)$ & \\
\hline \multirow[t]{4}{*}{353} & & $201.8(2)$ & $0.362(4)$ & 0 & $52(1)$ & \\
\hline & & $112(2)$ & $0.74(4)$ & $8(2)$ & $23(1)$ & \\
\hline & & $157(2)$ & $0.71(3)$ & $4(1)$ & $17(1)$ & \\
\hline & & $118(2)$ & $0.37(3)$ & 0 & $8(1)$ & \\
\hline \multirow[t]{4}{*}{$343^{*}$} & & 201.5(3) & $0.378(4)$ & 0 & $23(1)$ & \\
\hline & & $103(2)$ & $0.82(4)$ & $7(2)$ & $13(1)$ & \\
\hline & & $155(4)$ & $0.79(5)$ & $7(3)$ & $13(1)$ & \\
\hline & & $115(2)$ & $0.36(3)$ & $10.4(7)$ & $51(1)$ & \\
\hline \multirow[t]{2}{*}{363} & $\mathrm{HfF}_{4}($ Site I $)$ & $120(1)$ & $0.33(2)$ & $13.7(6)$ & $93(1)$ & \\
\hline & $\mathrm{HfF}_{4}($ Site II) & $109(2)$ & $0.91(4)$ & $2(2)$ & $7(1)$ & \\
\hline \multirow[t]{4}{*}{298} & $\mathrm{HfF}_{4}($ Site I) & $117(1)$ & $0.32(2)$ & $14.5(5)$ & $94(1)$ & \\
\hline & & $116(2)$ & $0.37(2)$ & $13(1)$ & & [3] \\
\hline & & $116(2)$ & $0.37(2)$ & $13(1)$ & & [9] \\
\hline & $\mathrm{HfF}_{4}($ Site II) & $111(2)$ & $0.82(3)$ & $3(2)$ & $6(1)$ & \\
\hline
\end{tabular}

* Taken after measurement at $353 \mathrm{~K} ;{ }^{\dagger}$ References not shown correspond to this work.

becomes monohydrate on heating or it becomes anhydrous $\mathrm{HfF}_{4}$ through the intermediate monohydrate. But, from our measurements, no signal corresponding to $\mathrm{HfF}_{4} \cdot \mathrm{H}_{2} \mathrm{O}$ has been observed (Table 1 ) at any temperature from 298 to $363 \mathrm{~K}$. The composition of the sample was found to be unchanged up to $353 \mathrm{~K}$.

The measurement was then repeated at $343 \mathrm{~K}$. Interestingly, the TDPAC spectra before and after the measurement at $353 \mathrm{~K}$ are found to be different (Fig. 1). The spectrum at $343 \mathrm{~K}$, after the measurement at $353 \mathrm{~K}$, shows dehydration of $\mathrm{HfF}_{4} \cdot 3 \mathrm{H}_{2} \mathrm{O}$ whereas at $353 \mathrm{~K}$ it showed no dehydration. In the second run at $343 \mathrm{~K}$, the dehydrated component (Site I of $\mathrm{HfF}_{4}$ ) increases from $8 \%$ to $51 \%$. This indicates that the dehydration temperature of the sample is $343 \mathrm{~K}$. In the first measurement at $343 \mathrm{~K}$ and subsequently at $353 \mathrm{~K}$ it was in the super heated state. Possibly, due to the presence of superheated crystalline state of the trihydrate tetrafluoride, it showed different dehydration temperature in the earlier measurements [3,4]. Probably, we could get the unchanged $\mathrm{HfF}_{4} \cdot 3 \mathrm{H}_{2} \mathrm{O}$ compound at a temperature higher than $353 \mathrm{~K}$ when its temperature was not reduced to $343 \mathrm{~K}$ and it is difficult to assign a definite dehydration temperature for this type of hydrated compound.

When the sample was heated at $363 \mathrm{~K}$, the components due to $\mathrm{HfF}_{4} \cdot 3 \mathrm{H}_{2} \mathrm{O}$ and $\mathrm{Hf}_{2} \mathrm{OF}_{6} \cdot \mathrm{H}_{2} \mathrm{O}$ disappear and the sample becomes anhydrous $\mathrm{HfF}_{4}$. Since at this temperature also no frequency component due to the monohydrate hafnium tetrafluoride has been observed, present experimental results do not support the process of dehydration through $\mathrm{HfF}_{4} \cdot 3 \mathrm{H}_{2} \mathrm{O} \rightarrow \mathrm{HfF}_{4} \cdot \mathrm{H}_{2} \mathrm{O} \rightarrow \mathrm{HfF}_{4}$ as reported earlier by Martínez et al. [3] and do not corroborate the Rickard's hypothesis that two water molecules of $\mathrm{HfF}_{4} \cdot 3 \mathrm{H}_{2} \mathrm{O}$ are weakly bound. The reason for getting contradictory results by Martínez et al. [3] probably lies in the fact that in the earlier sample [3], $\mathrm{HfF}_{4} \cdot 3 \mathrm{H}_{2} \mathrm{O}$ was produced along with $\mathrm{HfF}_{4} \cdot \mathrm{H}_{2} \mathrm{O}$. This monohydrate component was present throughout the temperature range even when the trihydrate becomes anhydrous at $330 \mathrm{~K}$. In the dehydrated sample, probably, the observed monohydrate component was not the dehydrated product of $\mathrm{HfF}_{4} \cdot 3 \mathrm{H}_{2} \mathrm{O}$, but the associate component of $\mathrm{HfF}_{4} \cdot 3 \mathrm{H}_{2} \mathrm{O}$. It seems that $\mathrm{HfF}_{4} \cdot \mathrm{H}_{2} \mathrm{O}$ is more stable for its dehydration to $\mathrm{HfF}_{4}$.

The second most intense $(25 \%)$ and the weakest component (8\%) of the sample can be understood from our TDPAC measurements at different temperatures from 323 to $363 \mathrm{~K}$ at $10 \mathrm{~K}$ intervals. From the Fourier spectra (Fig. 1) it is difficult to identify the weak components in the background of the strong component due to $\mathrm{HfF}_{4} \cdot 3 \mathrm{H}_{2} \mathrm{O}$. A best fitting (minimum $\chi^{2}$ ), however, has been obtained by considering four interaction frequencies. The second strong component has been shown in Figure 2 after subtracting the strongest component and two other weak components. The three Fourier peaks corresponding to this component can be identified in the subtracted spectrum.

It has been found that up to $353 \mathrm{~K}$, the spectra do not change much (Fig. 1). The site fractions for different components remain also almost the same (Fig. 3). These indicate that the sample does not dehydrate or transform on heating up to a temperature of $353 \mathrm{~K}$. At $363 \mathrm{~K}$, however, a change in the spectrum is clearly observed. The TDPAC spectrum obtained at $363 \mathrm{~K}$ 

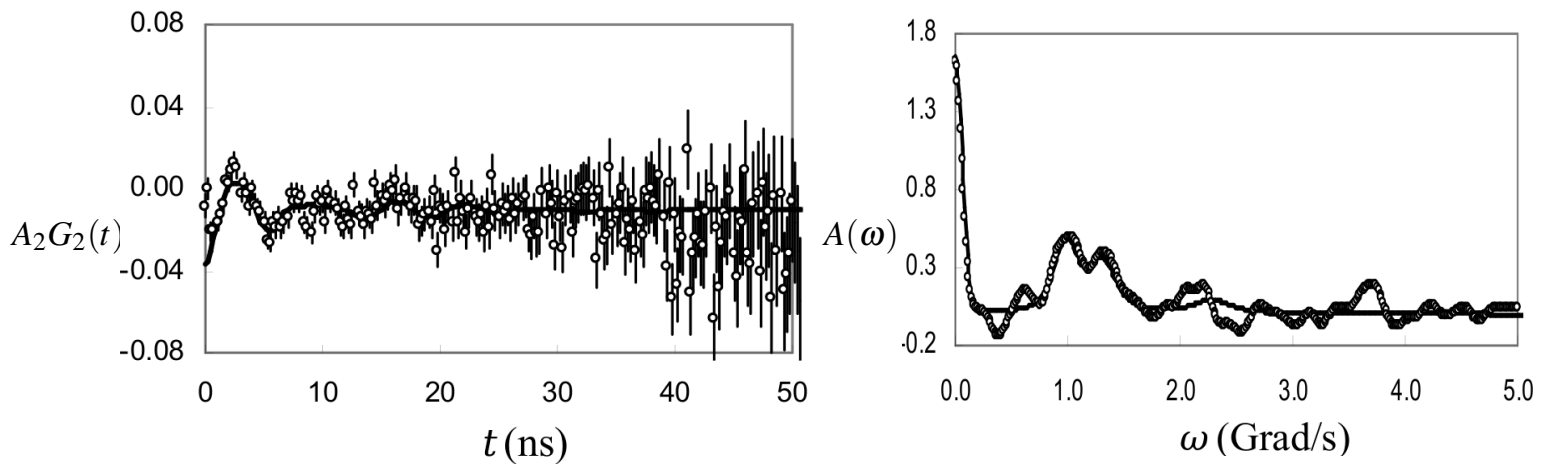

Fig. 2. The figure shows the second strong component due to $\mathrm{HfF}_{4}$ (Site II) after subtracting the strongest component and two other weak components corresponding to the measurement at $323 \mathrm{~K}$.

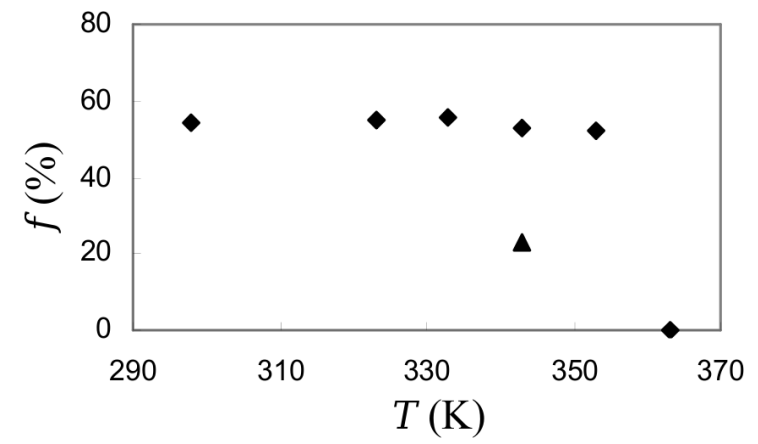

Fig. 3. Site fractions observed for the main component $\left(\mathrm{HfF}_{4} \cdot 3 \mathrm{H}_{2} \mathrm{O}\right)$ at different temperatures $(\bullet)$. At $343 \mathrm{~K}$, the fractions shown correspond to two different state of the sample. The Site percentage at $343 \mathrm{~K}$ drops to $\sim 50 \%(\boldsymbol{\Lambda})$ after the measurement at $353 \mathrm{~K}$.

is shown in Figure 1. An analysis of the spectrum shows that it can be better fitted by considering two frequency components rather than a single component. The corresponding values of $\omega_{\mathrm{Q}}, \eta$, and their population fractions are given in Table 1 . The most intense components (93\%) can be identified as $\mathrm{HfF}_{4}$. The values of $\omega_{\mathrm{Q}}$ and $\eta$ for this component are closer to the room temperature values in $\mathrm{HfF}_{4}$ reported earlier (Table 1). Since, the components due to $\mathrm{HfF}_{4} \cdot 3 \mathrm{H}_{2} \mathrm{O}$ and $\mathrm{Hf}_{2} \mathrm{OF}_{6} \cdot \mathrm{H}_{2} \mathrm{O}$ do not appear here, it can be considered that these components dehydrate at $363 \mathrm{~K}$ and converted to $\mathrm{HfF}_{4}$. After dehydration of the sample, the TDPAC measurement was performed at room temperature and the two components have been observed again at room temperature. These two components can, therefore, be attributed to two different sites of $\mathrm{Hf}$ in $\mathrm{HfF}_{4}$. From earlier measurements [3,9] in $\mathrm{HfF}_{4}$, only the strongest component (Site I) was reported. For the Site I component, the experimental values of $V_{z z}$ and $\eta$ showed an excellent agreement with the point charge model calculation for the $\mathrm{HfF}_{4}$ crystalline lattice [4], where only the eight nearest fluorine ions to the $\mathrm{Hf}$ ion were taken into account. The crystal structure of this compound can be found in [10]. Although the value of $\omega_{\mathrm{Q}}$ for the weaker component (Site II) has been found to be not much different from that of the stronger component (Table 1), a higher value of the asymmetry parameter $(\eta=0.82)$ and a lower value of $\delta(\sim 0)$ has been obtained for the weaker component. This suggests that for the two sites of Hf, the $V_{z z}$ and, therefore, the charge distributions are similar, but the fluorine ions have different orientations with respect to the Hf ion producing a different value of $\eta$. The Site II in the anhydrous $\mathrm{HfF}_{4}$ has been found to be only $\sim 7 \%$. The major fractions occupy Site I.

At room temperature and below $363 \mathrm{~K}$, the two components that appear along with the components of $\mathrm{HfF}_{4} \cdot 3 \mathrm{H}_{2} \mathrm{O}$ and $\mathrm{Hf}_{2} \mathrm{OF}_{6} \cdot \mathrm{H}_{2} \mathrm{O}$ can also be assigned as two sites of anhydrous $\mathrm{HfF}_{4}$. But, before any chemical transformation of the sample occurs, the two site fractions are opposite to when it is transformed. Before transformation, Site I in $\mathrm{HfF}_{4}$ occupies only $20-25 \%$ whereas Site II occupies $75-80 \%$ of the total $\mathrm{HfF}_{4}$ sites. Also, for Site I, in contrast to large width of frequency distribution $(\delta \sim 14 \%)$ in the anhydrous $\mathrm{HfF}_{4}$, it shows a very good crystalline nature $(\delta=0)$ in the hydrated sample.

\section{Conclusions}

From present TDPAC measurements at different temperatures, dehydration of trihydrate hafnium tetrafluoride to anhydrous tetrafluoride has been observed The present investigation shows that this com- 
pound dehydrates directly to anhydrous tetrafluoride without producing any monohydrate tetrafluoride as an intermediate product. This is in disagreement with the earlier results which reported that i) the trihydrate hafnium tetrafluoride dehydrates through the intermediate monohydrate and ii) the two water molecules of the trihydrate are weakly bound. However, the present results support the idea of Martínez et al. [3] that the final dehydration product of $\mathrm{HfF}_{4} \cdot 3 \mathrm{H}_{2} \mathrm{O}$ is $\mathrm{HfF}_{4}$ and not $\mathrm{Hf}_{2} \mathrm{Of}_{6} \cdot \mathrm{H}_{2} \mathrm{O}$ or $\mathrm{HfF}_{4} \cdot \mathrm{H}_{2} \mathrm{O}$ when heated in air as found by Rickard and Water [1] and Gaudreau [2], respectively. It has been found that the compound $\mathrm{HfF}_{4} \cdot 3 \mathrm{H}_{2} \mathrm{O}$ can remain stable up to a temperature of $353 \mathrm{~K}$ although its dehydration temperature has been observed to be $343 \mathrm{~K}$. At $353 \mathrm{~K}$, it remained in the super heated state and this super heated state becomes normal when the temperature is reduced by $10 \mathrm{~K}$.

The anhydrous $\mathrm{HfF}_{4}$ gives two different TDPAC signals corresponding to two different Hf sites. The
Site I which is the strongest in anhydrous $\mathrm{HfF}_{4}$ was also found in earlier measurements (Table 1) but Site II $(\sim 7 \%)$ with higher value of asymmetry parameter has been observed in the present study only. Both the Site I and II appears in the hydrated sample also. The Site II has been found to be stronger before the sample was dehydrated. During chemical transformation of the sample at $363 \mathrm{~K}$, the site populations have been reversed. However, the presence of two Hf sites in $\mathrm{HfF}_{4}$ has been confirmed from measurements in both hydrated and dehydrated sample.

At the end, we can conclude with the remark that time-differential perturbed angular correlation has proven here to be a useful nuclear technique for microscopic analysis of chemical sample.

\section{Acknowledgement}

The author wishes to thank Professor Dr. T. Butz of University of Leipzig, Germany, for his help in data analysis.
[1] C. E. F. Rickard and T. N. Waters, J. Inorg. Nucl. Chem. 26, 925 (1964).

[2] B. Gaudreau, Compt. Rend. Acad. Sci. (Paris) 263C, 67 (1966)

[3] J. A. Martínez, M.C. Caracoche, A. M. Rodríguez, P. C. Rivas, and A. R. López García, Chem. Phys. Lett. 102, 277 (1983).

[4] M. C. Caracoche, J. A. Martínez, P. C. Rivas, and A. R. López García, Hyperfine Interact. 23, 221 (1985).

[5] G. L. Catchen, Mat. Res. Bull. XX, 37 (1995).

[6] G. Schatz and A. Weidinger, in: Nuclear condensed matter physics; nuclear methods and application (translated by J. A. Gardner), John Wiley and Sons, Chichester, New York, Brisbane, Toronto, Singapore 1996, p. 63.

[7] C. C. Dey, Pramana 70, 835 (2008).

[8] C. C. Dey, Hyperfine Interact. 175, 185 (2007).

[9] W. G. Thies, H. Appel, R. Heidinger, and G. M. Then, Hyperfine Interact. 30, 153 (1986).

[10] R. W. G. Wyckoff, Crystal structures, Vol. 2, WileyInterscience, New York 1965, p. 129. 